\title{
STRUCTURAL DESIGN OF A PRACTICAL LARGE-SPAN CABLE-FRAME TYPE OF SUSPENDED SINGLE-LAYER RETICULATED SHELL WITH FREE SURFACE
}

\author{
Zhi-hong Zhang ${ }^{1, *}$ and Shi-lin Dong ${ }^{2}$ \\ ${ }^{1}$ Shanghai Normal University,200234, China; \\ ${ }^{2}$ Zhejiang University, 310027, China \\ *(Corresponding author: E-mail: zhangzh@zuaa.zju.edu.cn)
}

Received: 26 February 2011; Revised: 17 March 2011; Accepted: 24 March 2011

\begin{abstract}
Cable-frame type of suspended single-layer reticulated shells with free surface proposed by the author of the present paper is a novel type of large-span hybrid spatial structures. The whole design procedure regarding a practical gymnasium steel roof using this structural system is presented. System constitution including form finding of the upper structure and shape determination analysis of the lower cable-bar system is given out in details and emphasized. Load/action effects are thoroughly summarized for member sections design. A special joint design when diagonal cables penetrating the corresponding upper steel beam member is also brought forward. Hopefully the present paper could benefit the further research and practical engineering on hybrid spatial structures.
\end{abstract}

Keywords: Suspended single-layer reticulated shell, Shape determination analysis, Spatial cable frame, Hybrid spatial structures, Joint design

\section{INTRODUCTION}

Space structures hybridizing a stiff system and a flexible cable-bar system (a single-layer reticulated shell with free surface plus a cable-bar tension system) are designated as hybrid spatial structures. Cable-stayed or suspension lattice shells, planar/spatial beam/truss-string structures, and spherical suspend-domes are all hybrid spatial structures and have been built world widely. Theoretical study and reports on practical engineering experiences disperse numerously in journal papers. This is not convenient for scholars or structural engineers to learn of or solve a certain problem.

\section{Past Work on Spherical Suspen-domes}

Kawaguchi et al. [1, 2] proposes a spherical hybrid spatial structures designated as "Suspen-dome" more than 15 years ago. Finite element method (FEM) analysis and structural model test on a suspen-dome with a diameter of $3 \mathrm{~m}$ and a rise of $0.45 \mathrm{~m}$ concluded that the axial force within the lattice member of suspen-dome is about $1 / 3$ of corresponding members of the single-layer reticulated shell when working independently. Static non-linear geometrical stability of the suspen-dome is about 1.5 times of that of the single-layer lattice shell. An ideal $200 \mathrm{~m}$-span suspen-dome is analyzed and suggests a possible application of suspen-dome to very large-span roofs [2]. Tatemichi et al. [3] conducts a vibration test on a full-size suspen-dome. Kang et al. [4] presented their work on some problems of the structural design of suspen-domes. Zhang et al. [5-6] proposes a universal strategy-local analysis method for force finding analysis of hybrid space structures such as beam-string structures, suspen-domes, and other kinds of hybrid space structures. A rib-ring type of suspen-dome with lower cable-bar system of Geiger type was studied. Construction feasibility due to compatibility requirement of the upper single-layer reticulated shell is put forward. Zhang [7] emphasizes on the optimal pre-stress distribution by using genetic algorithm. Chen et al. [8] propose a rigid suspen-dome for the roof of the VIP hall of Tianjin museum. An experiment was performed under static load. Zhang et al. [9] gives out the whole structural design procedure in details with respect to the largest spherical suspen-dome built in the world at present. A new force finding 
analysis strategy designated as linear deduction method is presented. This suspen-dome is also the first one adopting rib-ring type of lower cable-bar system. Zhang [10] developed a universal computational algorithm for shape determination problem of general hybrid spatial structures.

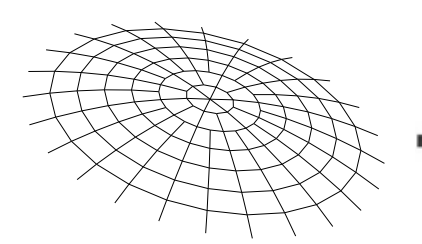

Rib-ring type of reticulated shell

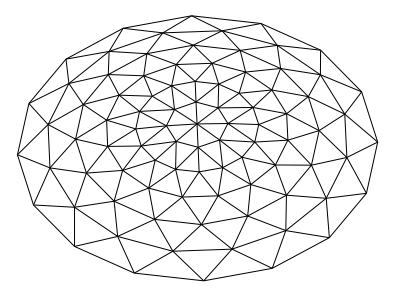

Sunflower type of lattice shell

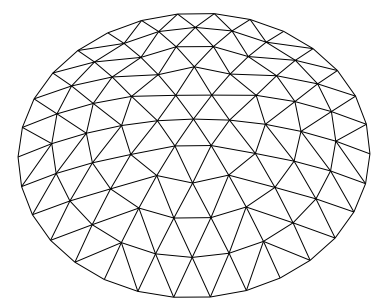

Kiewit type of lattice shell

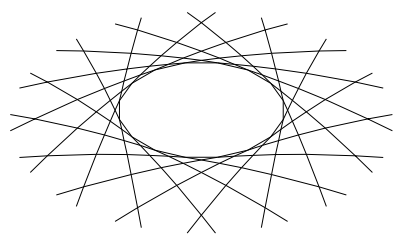

Bird-nest type of lattice shell

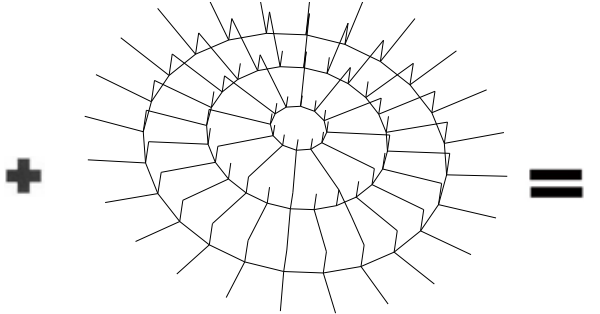

Rib-ring type of cable-bar system

(a) Rib-ring type of suspen-dome

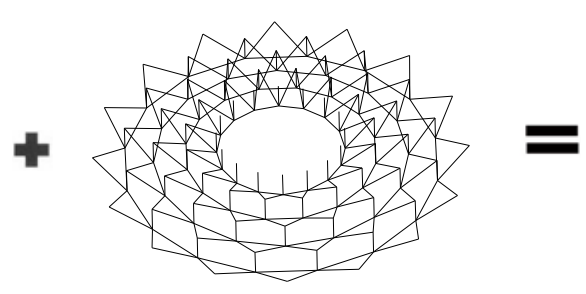

Sunflower type of cable-bar system

(b) Sunflower type of suspen-dome

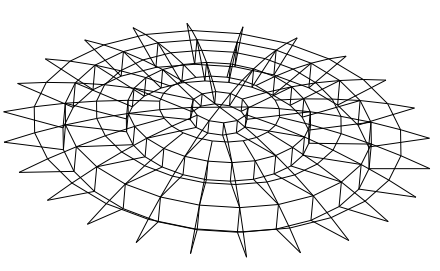

Rib-ring type of suspend-dome

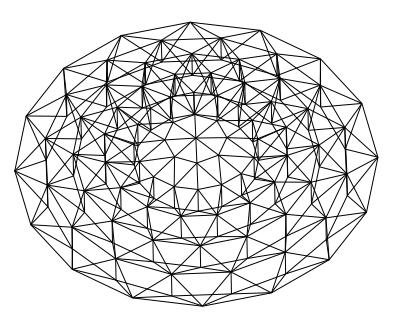

Sunflower type of suspend-dome

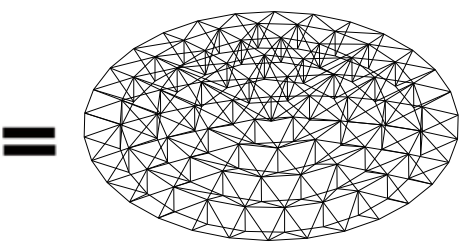

Kiewit type of suspen-dome

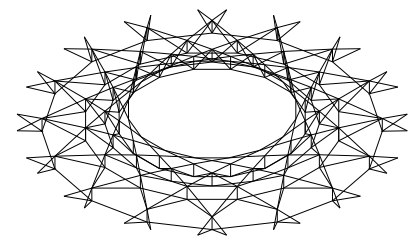

Bird-nest type of suspen-dome

Sunflower type of cable-bar system (d) Bird-nest type of suspen-dome

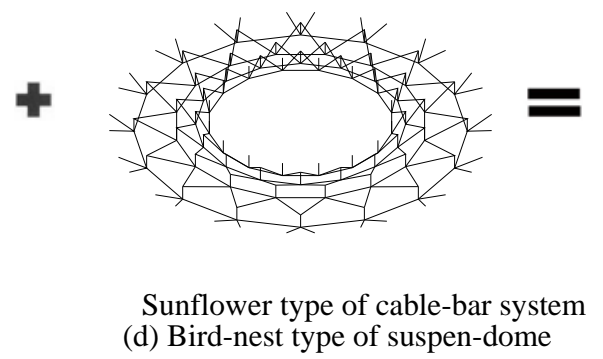

Figure 1. Basic Types of Spherical Suspen-dome

\section{Basic Types of Spherical Suspen-domes}

Spherical suspend-domes can be classified by several characteristics of their upper structures and lower cable-bar system.

(1) According to different forms of lower cable-bar system rib-ring type (Figure 1a), sunflower type (Figure 1b), and Kiewit type (Figure 1c) of spherical suspend-domes are given out in Figure 1. 
(2) On the basis of the lattice forms of the upper single-layer reticulated shell, they can be called as rib-ring type, sunflower type, Kiewit type, and bird-nest type of suspen-dome.

It should be pointed out that the lattice form of the upper single-layer reticulated shell could commix Kiewit type and sunflower type or others. The same to the lower cable-bar distribution.

\section{Characteristics of Spherical Suspen-domes}

[1] Maximum axial internal forces within the upper structure of suspen-dome reduce to $1 / 3$ or so of that of an individual single-layer reticulated shell under same downward dead load. The upper and lower structures work together. Thus the ultimate load-carrying capacity ability of the whole system is higher too.

[2] Not only the lower cable-bar system but also the upper stiff structure need shape determination analysis. This is usually ignored in practical engineering.

[3] Suspen-dome can constitute a self-equilibrated system dependent on the abutment styles.

\section{Representative Suspen-domes Built in China}

Figure 2 gives out the system constitution of the Peking Olympic game tennis arena, built in 2006, with a span of $93 \mathrm{~m}$ in Peking Industry University. This spherical suspend-dome contains 5 loops of sunflower type of lower cable-bar system. Figure 3 is lotus arena in Jinan city, built in 2008, with a diameter of $122 \mathrm{~m}$. A Sunflower-Kiewit hybrid lattices is adopted for the upper spherical single-layer reticulated shell. This spherical suspend-dome composes of 3 loops of rib-ring type of lower cable-bar system. Figure 4 is Yubei gymnasium in Chongqing city, Sichuan province in China. Pyramidal shape is distinctive. Figure 5 shows Nansha gymnasium in Guangzhou city in China, built in 2009, with a diameter of $98 \mathrm{~m}$. The author of the present paper does not know that there exists this gymnasium until finishing designing Yueqing Olympic center and preparing this paper. Someone might deem it a spatial beam-string structure. Single beam-string structure substitutes stiff beam members for the upper chord cable of single planar cable-frame. This roof system is actually a cable-frame type of suspended rib-ring type of single-layer reticulated shell. The difference between spatial beam-string structures and cable-frame type of suspended single-layer reticulated shells lies in the circular member of the upper lattice shell. Ideal spatial beam-string structures these circular members are for purpose of out of plane instability. Thus they should be pin-jointed with radial members. Anyway this is not important with respect to denominating an attractive structural system.

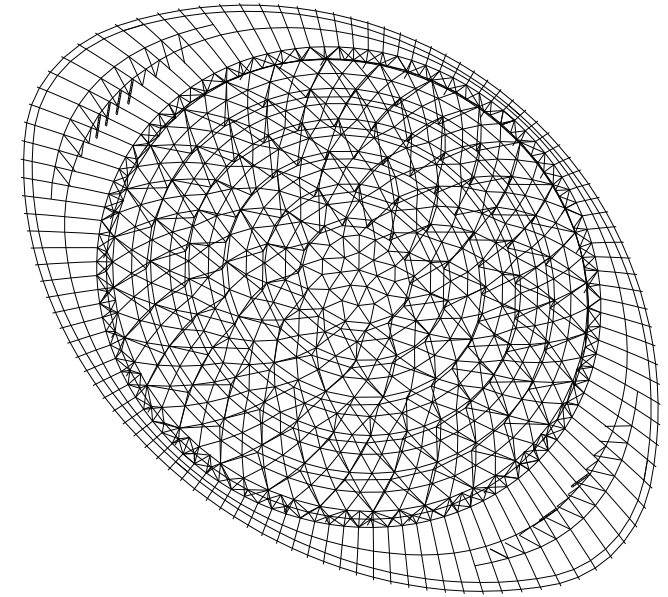

Figure 2. Peking Industry University Tennis Arena 


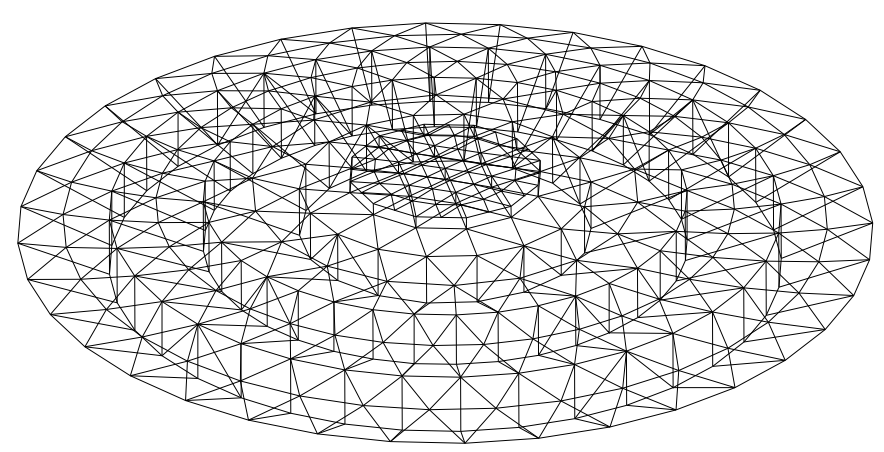

Figure 3. Jinan Olympic Center Lotus Arena

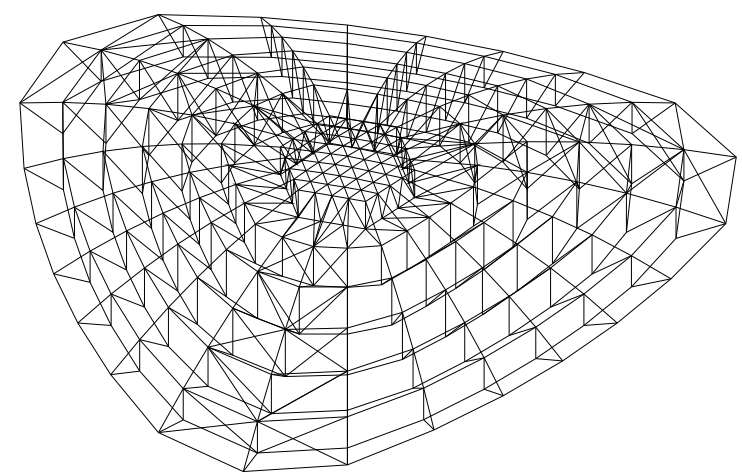

Figure 4. Chongqing Yubei Gymnasium

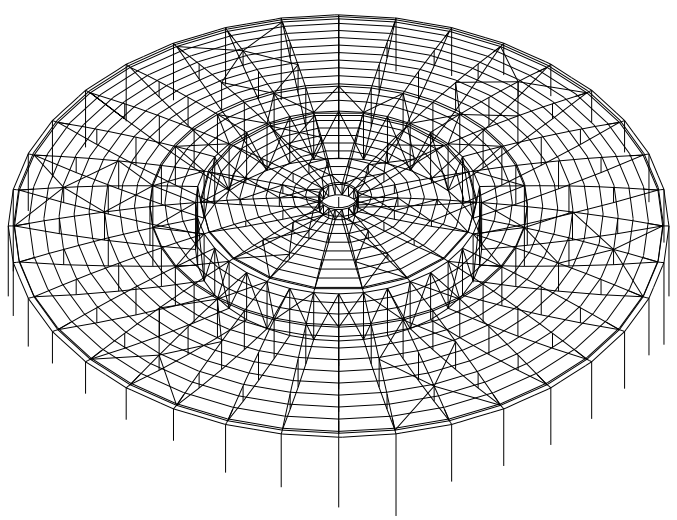

Figure 5. Guangzhou Nansha Gymnasium

\section{Development of Suspended System}

Upper single-layer reticulated shells with free surface plus lower cable-dome [11-12] type or cable-frame [13] type of cable-bar system is herein designated as suspended single-layer reticulated shells with free surface (Figure 6). This appellation comprises suspen-dome with spherical single-layer reticulated shells, suspended cylindrical single-layer reticulated shells, spatial beam/truss-string structures, and other suspended systems.

Basic types of suspended single-layer reticulated shells

(1) According to the character of the upper single-layer reticulated shell with free surface, it can be classified as suspended single-layer reticulated shells with regular (there exists algebra equation) or irregular free surface. 
(2) On the basis of the cable-bar system distribution, there are cable-dome type and cable-frame type of suspended single-layer reticulated shells with free surface.

Characteristics of suspended single-layer reticulated shells

(1) System constitution is simple. Indoor and outdoor architectural effects are good.

(2) The upper structure member internal forces distribute evenly and the whole system is more stable than an individual single-layer reticulated shell with free surface.

(3) Shape determination analysis of the lower cable-bar system is indispensable and of most importance. If possible form-finding analysis of the upper reticulated shell could be carried out by structural engineers. Hoop cable in common sense will be not in a horizontal plane and paunch bars will be not vertical any more.

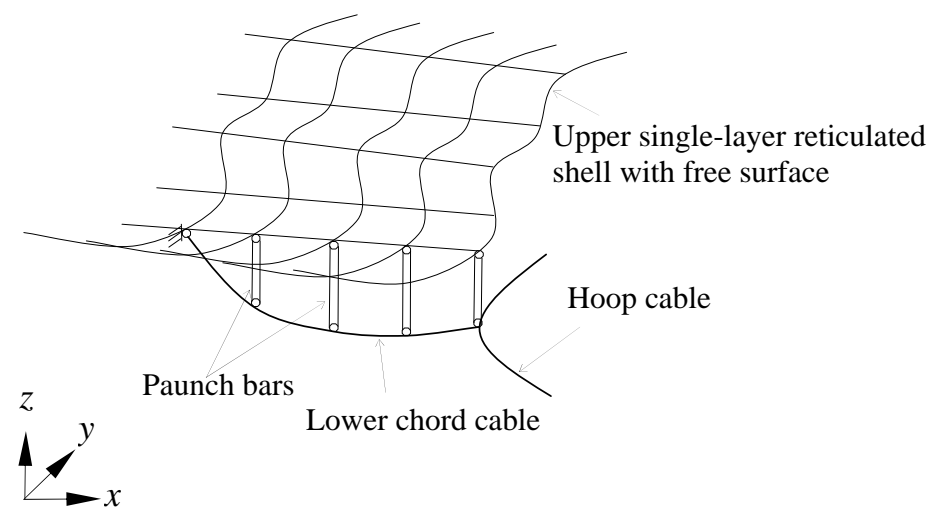

Figure 6. Suspended Single-layer Reticulated Shell with Free Surface

\section{Cable-frame type of suspended single-layer reticulated shell with free surface in practice}

The author of the present paper just finished designing Yueqing Olympic center composed of a stadium and two arenas (main gymnasium and swimming arena adopt the same structural system, but the span of the gymnasium is larger than that of the swimming arena). The gymnasium (Figure 7-8) composes of a rigid supporting system (inclined V-shaped columns and upper and lower ring-beams), an upper rib-ring type of single-layer reticulated shell with minimal surface, and a cable-frame type of lower cable-bar system which penetrates the upper corresponding radial beams. Plan view of the whole roof system is an ellipse with long axis span $148 \mathrm{~m}$ and short axis span $128 \mathrm{~m}$. The top level of the upper horizontal ring-beam is $28 \mathrm{~m}$. Metal roof covering materials are adopted. There is a circular center at top of the inner roof with a diameter of $40 \mathrm{~m}$ at a level of $25 \mathrm{~m}$. This inner circular plane is divided into 8 and 24 grids. The minimal surface shell is divided into 24 grids as rib-ring shaped. The lower chord cable, paunch bars and paunch cables, and spatial hoop cables constitute a stable lower cable-bar system. Figure 7 gives out the constitution of the whole system. Figure $7 \mathrm{a}$ is the stiff grid structures. Figure $7 \mathrm{~b}$ is the flexible tension system. By combining Figure $7 \mathrm{a}$ and Figure $7 \mathrm{~b}$ a novel cable-frame type of suspended single-layer reticulated shell is shown in Figure 7c. Figure 8 provides the south, west and sectional elevation of the whole system. From Figure 8 it is noted that the hoop cable is not in a horizontal plane and is also not circular. This is rational due to a non-evenly distributed spatial flexibility in vertical direction of the upper reticulated shell and supporting system. Figure 8c shows that the lower chord cable penetrates the corresponding upper radial beam, thus it is a continuous cable. Paunch bars and paunch cables provide proper supporting or hauling action on the reticulated shell. Lower chord cable is more efficicent. It is noted that paunch members are not vertical. Inside and under this steel roof system there is the reinforced concrete structure which is well separated except necessary link-beams when designing foundations. 


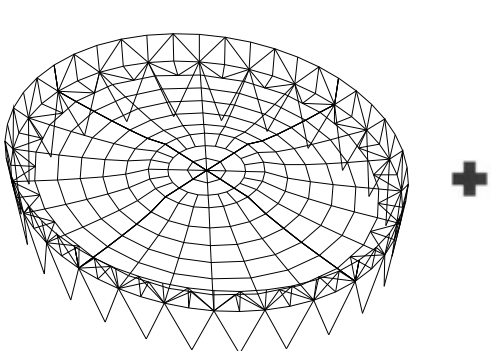

(a)

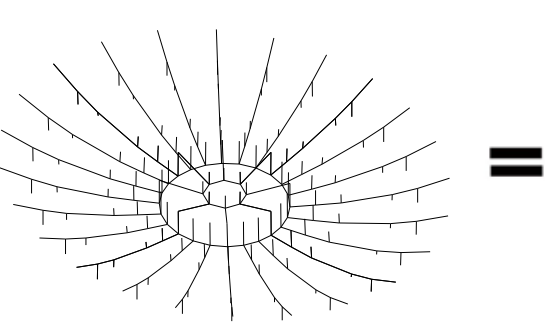

(b)

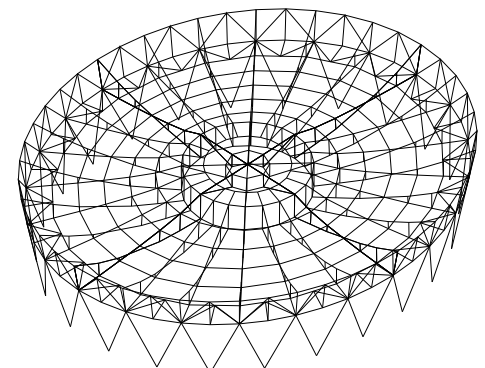

(c)

Figure 7. Yueqing Olympic Center Gymnasium

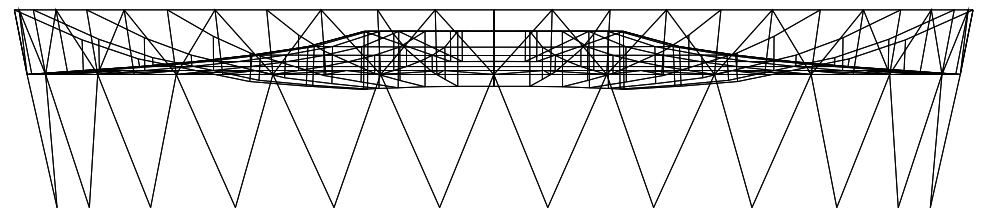

(a) West Direction Elevation

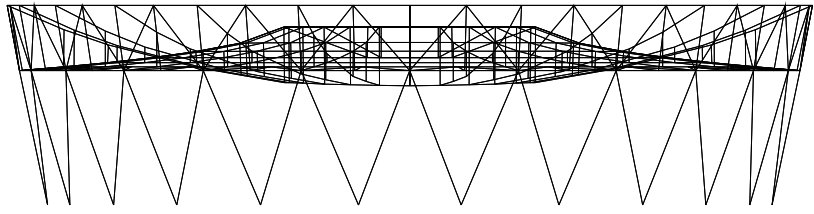

(b) South Direction Elevation

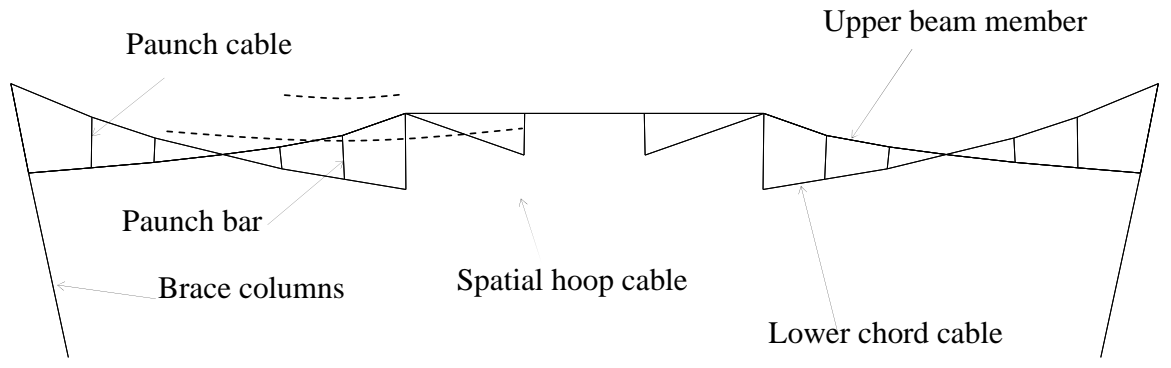

(c) South Sectional Elevation

Figure 8. South and West Elevations

The design procedure put forward in the present paper is basically the same for a 2-phase design of tensioned structures. a) Shape determination analysis, and b) Load/action effects analysis. Emphasis is herein addressed on the shape determination analysis of this steel roof system. Form finding analysis of the upper single-layer reticulated shell is conducted using force density method and scattered data interpolation techniques. Shape finding of the lower cable bar system is based on the computational algorithm given out in the reference [10]. Hence in Section 2 it focuses on the details and results of computation process. In section 3, load/action effects such as gravity load due to self-weight of structural members and appended mechanical and electric facilities, wind load, environmental temperature variation, and seismic load for etc. are shortly summarized. In Section 4 some details of special joints of this roof system is put forward. 


\section{SHAPE DETERMINATION ANALYSIS-CONSTITUTING SYSTEM}

Shape determination analysis is the first step of structural design. How to constitute the whole system according to architectural design concept or requirements is emphasized in this section.

\subsection{Fundamental Theory}

Some computational tools including dynamic relaxation method, force density method, scattered data interpolation, and local analysis method for the structural design of cable-frame type of suspended single-layer reticulated shells are briefly introduced in this section.

\section{Dynamic relaxation method}

Dynamic relaxation method [15-16] has been popularly used in many numerical analysis fields such as linear elastic analysis of thin shells and vaults, load analysis of spatial or planar frames and form finding or load analysis of tensile structures. The pseudo mass or pseudo damping is used to change a static problem into a dynamic one, so it is also called as pseudo transient analysis method. The most important advantage of DRM is that it is a lucid and stable automatic algorithm and needs less memory of computer. It works well to get the accurate solution of the problems which FEM cannot solve easily, such as form finding analysis of tensile structures and load analysis of zero initial stiffness system.

\section{Force density method}

Force density method was put forward by H. J. Schek in 1974 in application to form finding analysis of cable-nets [17]. Assuming a certain force density value (usually it refers to ratio of axial tension to the length of the corresponding member), on the basis of the nodal equilibrium conditions a linear algebra equation group about the nodal coordinates can be obtained. Solve this linear algebra equation group to get the final spatial shape of cable-nets or other membrane structures. The present paper utilizes force density method for shape finding analysis of the minimal surface of the upper single-layer reticulated shell. For pure form finding analysis problems force density method is lucid and fast. But it is found that the final shape is closely related with the value of force density and the grid topology.

\section{Scattered data interpolation}

After form finding analysis using force density method of the upper single-layer reticulated shell, it is necessary to carry out scattered data interpolation for a proper roof grid. It is because of the final grid shape and size given out by force density method might not be suitable for practical engineering and distribution of the lower cable-bar system. Theory of scattered data interpolation can be found in the references [18-19]. The present paper develops a short program using Matlab.

\section{Local analysis method}

General hybrid spatial structures are composed of two parts: the upper structure and the lower structure (Figure 7a and Figure 7b). Sequence of Local analysis method [6] in application to pure force finding analysis of hybrid spatial structures is from the lower part (Figure $7 \mathrm{~b}$ ) to the upper part (Figure 7a). The geometrical configuration of the lower cable-bar system is artificially determinate in advance. The equivalent upward axial forces of the lower system at the upper node of vertical bars is equal to the reaction force of the upper structure (Figure 9) at added supports under self-weight load and others. Local analysis method is also available for shape determination 
problem of hybrid spatial structures. But computational sequence is from the upper part to the lower part since the geometrical configuration is unknown beforehand.

The equivalent upward support in vertical bars of lower system (Figure 10) is equal to the reaction force from the upper structure (Figure 9) under additional gravity loads and self-weight of beam members. This can be understood as appending vertical zero-displacement constraints to the upper structure (Figure 9). By linear elastic analysis of the upper structure as shown in Figure 9, vertical reaction forces can be obtained. If additional gravity loads and the self-weight of beam members of the upper structure ideally distribute in a certain way, vertical bars of the lower system will be still vertical and their design pre-compression $t_{V B i}(i=1,2, \cdots, n)$ will be equal to the reaction forces (Figure 10). Further explanation of shape determination problem of hybrid spatial structures is presented in the reference [10].

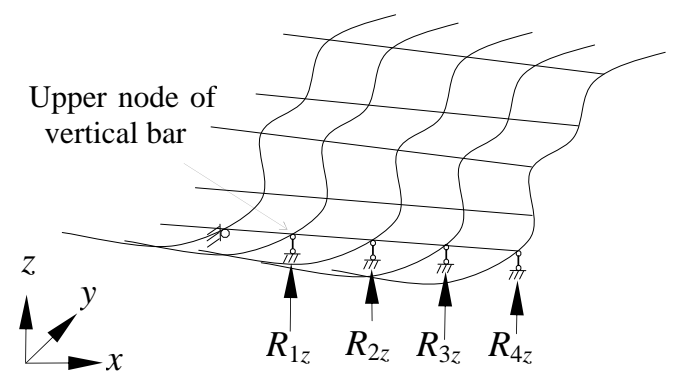

Figure 9. The Upper Structure (Single-layer Reticulated Shell with Free Surface)

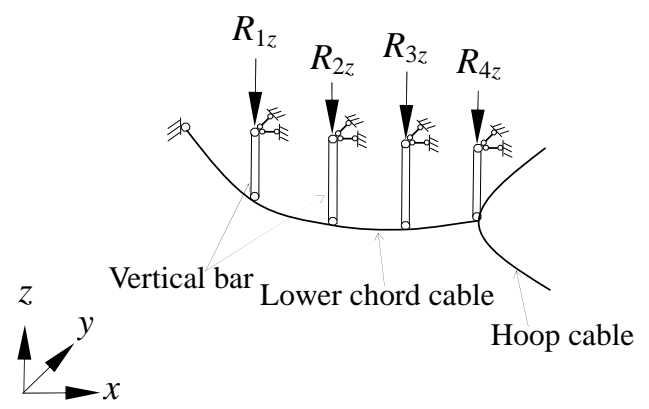

Figure 10. The Lower Structure

\subsection{Form Finding of the Upper Single-layer Reticulated Shell}

The supporting system including the upper and lower steel ringbeams and $\mathrm{V}$ shaped inclined columns is decided by the architect. And it is also known at first that there is a circular inner plane with a diameter of $40 \mathrm{~m}$ at a level of $25 \mathrm{~m}$. According to this information a rough model is built as shown in Figure 11a and Figure 11b.

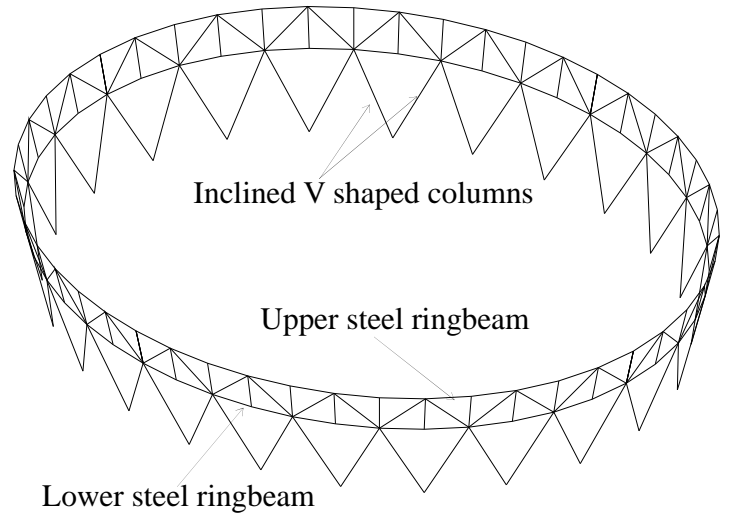

(a) Supporting System Decided by Architects 


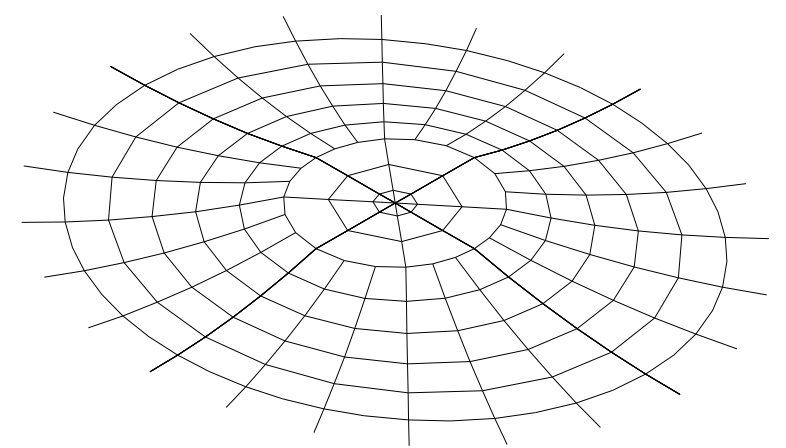

(b) Rough Grid of the Upper Reticulated Shell

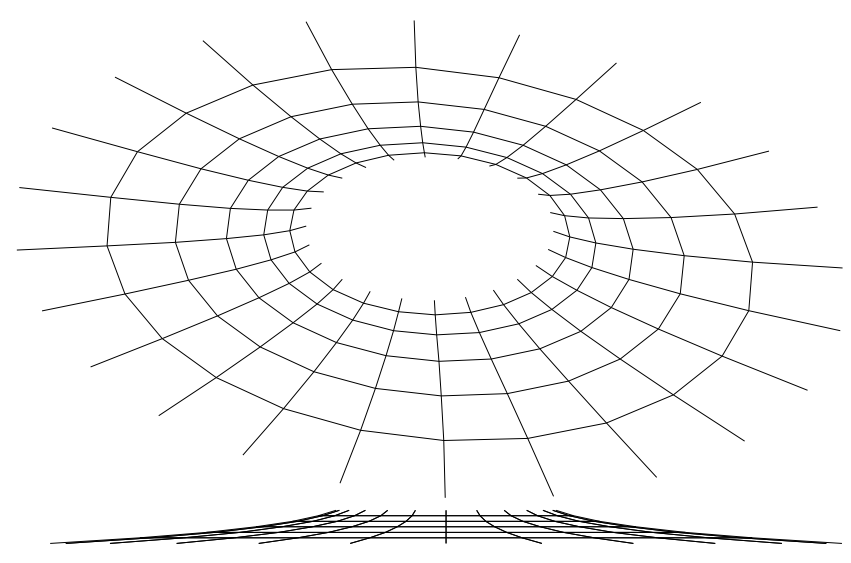

(c) Minimal Surface of the Upper Reticulated Shell after Form Finding using Force Density Method

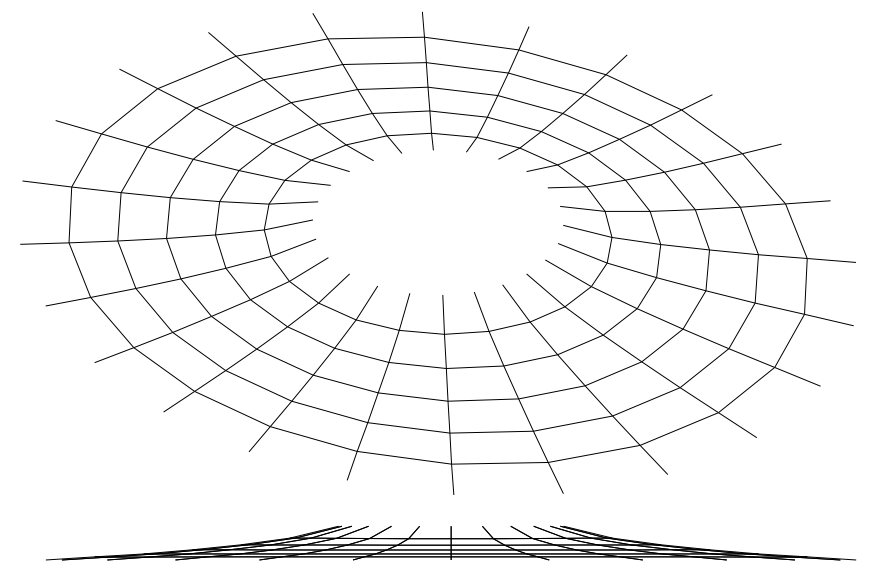

(d) Minimal Surface after Interpolation

Figure 11. Form Finding Analysis and Scattered Data Interpolation

Shape geometry in Figure 11a is known at first from architectural design. The upper and lower steel ringbeams are horizontal deposited. The upper steel ringbeam is designed with an outer diameter of $1700 \mathrm{~mm}$ with C40 concrete inside. The central inner circle at a level of $25 \mathrm{~m}$ is also decided by architects. Thus only the lattice shape between the inner circle and the lower ringbeam is left for structural engineer. Figure 11b gives out a rough grid shape for form finding analysis by using force density method. Figure 11c shows the final shape after form finding. It is noted that the 
cicular members is at intervals of $1 \mathrm{~m}$. Figure 11d is from Figure 11b and Figure 11c by scattered data interpolation. $x$ and $y$ direction nodal coordinates in Figure 11d is the same with that in Figure 11b. $z$ direction coordinate is interpolated on the minimal surface of Figure 11c. A short program is developed by Matlab as follows.

Interpolation.m

load originalxy.txt

ox=originalxy(:,3);

oy=originalxy(:,4);

load newxyz.txt

$n x=$ newxyz(:,3);

ny=newxyz(:,4);

$\mathrm{nz}=\mathrm{newxyz}(:, 5)$;

Z=griddata(nx,ny,nz,ox,oy);

plot3(ox,oy,Z,'o'), hold on

After these steps above, there is another step to decide the section size of the stiff system including the supporting system and upper single-layer reticulated shell. This can be conducted by using commercial structural design \& analysis software such as Sap 2000 or Midas Gen. A rough geometry of lower cable-bar system is shown in Figure 12a. In case of section size determination of stiff system cables and bars are attached and are assumed to be two-node beam elements without pretension inside. Next to section size selection of the stiff system according to stress check or deflection control or stability capacity ability, it is needed to do shape determination analysis of lower cable-bar system on the basis of reaction forces in vertical direction due to gravity load, i. e., 1.0 times of dead load including self-weight of the stiff beam members and appended roof covering materials.

\subsection{Shape Determination Analysis of the Lower Cable-bar System}

Shape determination analysis is conducted utilizing computational algorithm put forward in the reference [10]. That computational algorithm is universally available for hybrid spatial structures by using Model A and Model B. These two models differ with each other on the boundary conditions. Dynamic relaxation method and local analysis method are combined for a stable surface shape finding of the lower node positions of paunch bars and cables. Figure 12b gives out the final shape of the lower cable-bar system. The main difference between Figure 12a and Figure 12b lies in the hoop cable spatial shape. An adaptive cable-bar system contains a spatial hoop cable on a saddle-like surface to provide necessary support for upper single-layer reticulated shell. 


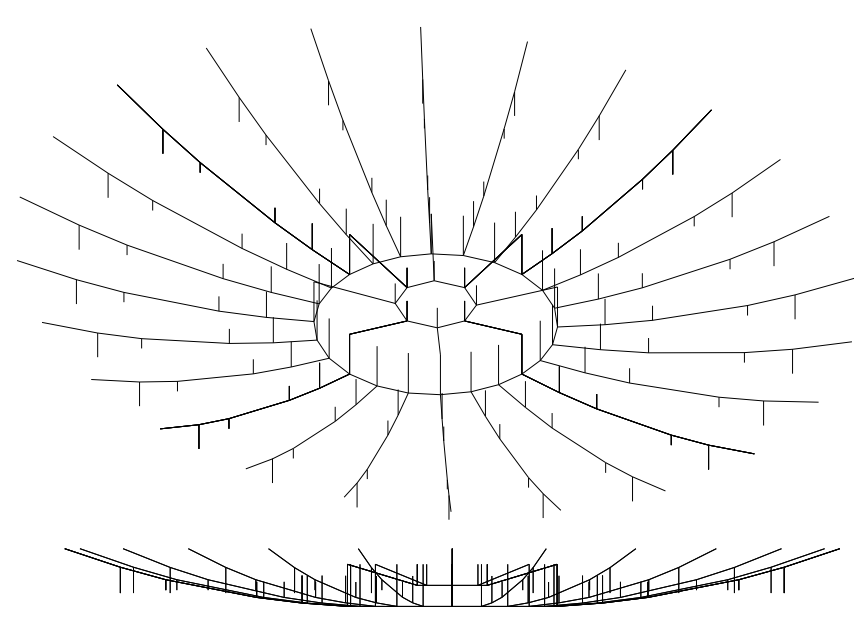

(a) Rough Shape of the Lower Cable-bar System

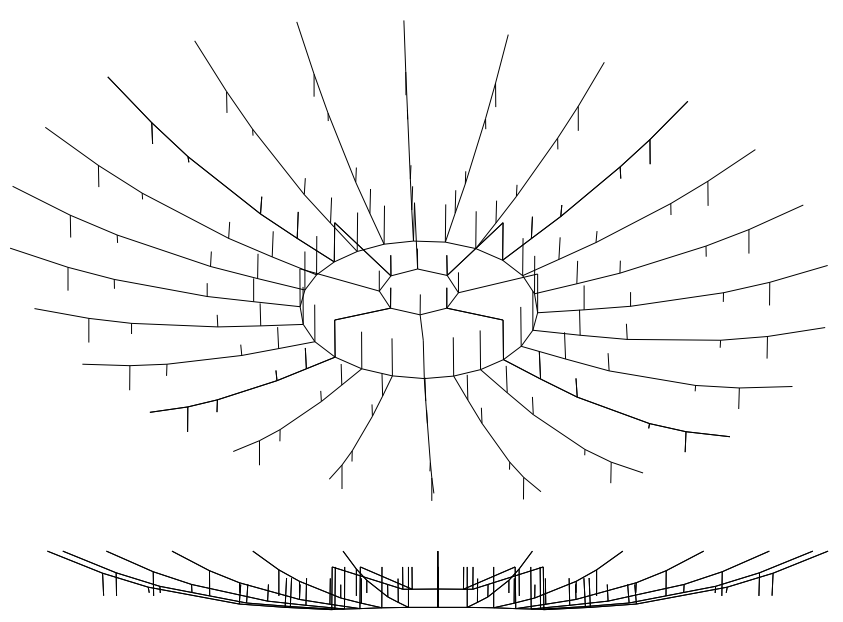

(b) Final Shape of Lower Cable-bar System after Shape Determination Analysis

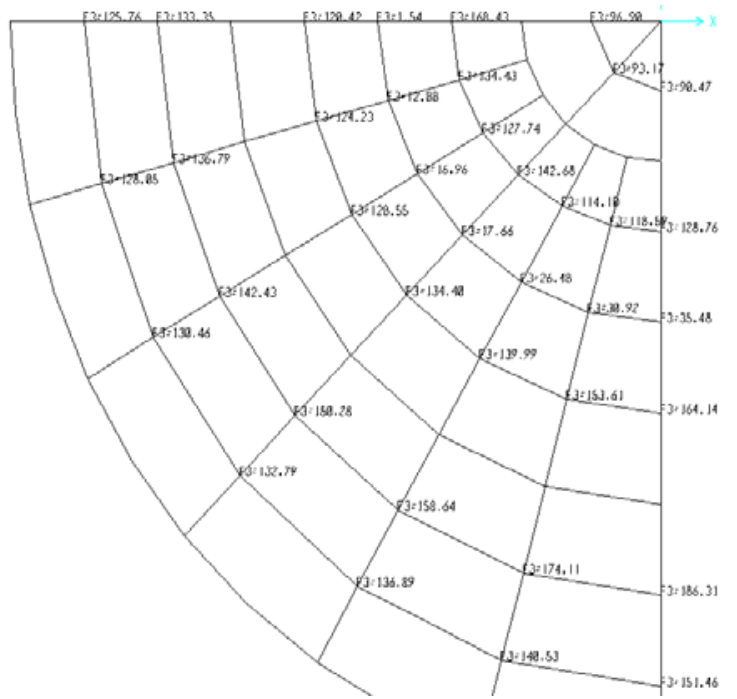

(c) Reaction Force in Vertical Direction/kN

Figure 12. Shape Determination Analysis of Lower Cable-bar System 
Figure 12c is the reaction force in vertical direction from the stiff system under dead load. For precise shape determination analysis of lower cable-bar system it is needed to take account of the self-weight of the cables and bars. Iterative work from Figure 12b to Figure 12c is indispensable. After shape determination analysis of lower cable-bar system the pretension level and distribution are obtained at the same time. Then, it is easy to select proper sections of cables and bars. Table 1 gives out the final section size of each member. Table 2 shows the final pretension level and distribution of lower cable-bar system. Figure 13 is the element number of a quarter of lower cable-bar system.

Table 1. Section Size of All Members

\begin{tabular}{|c|c|c|}
\hline Member name & Section size & $\begin{array}{l}\text { Material/stan } \\
\text { dard } \\
\text { breaking } \\
\text { capacity } \\
\text { ability }\end{array}$ \\
\hline V-shaped inclined column & $\mathrm{P} 900 \times 25$ & Q345B \\
\hline Steel column between ringbeams & $\mathrm{P} 900 \times 25$ & Q345B \\
\hline Upper ringbeam & $\begin{array}{l}\text { P1700×35 with C40 } \\
\text { concrete inside }\end{array}$ & Q345B \\
\hline Lower ringbeam & $\mathrm{P} 1000 \times 30$ & Q345B \\
\hline Paunch members between ringbeams & P325 $\times 12$ & Q345B \\
\hline Radial beams of outmost ring & $\mathrm{B} 900 \times 400 \times 30 \times 30$ & Q345B \\
\hline Other radial beams & $\mathrm{B} 600 \times 400 \times 16 \times 20$ & Q345B \\
\hline $1^{\text {st }}$ ring members & P219×8 & Q345B \\
\hline $2^{\text {nd }}$ and $3^{\text {rd }}$ ring members & $B 600 \times 400 \times 16 \times 20$ & Q345B \\
\hline $4^{\text {th }}-7^{\text {th }}$ ring members & $\mathrm{P} 273 \times 10$ & Q345B \\
\hline $8^{\text {th }}$ ring members & $\mathrm{P} 402 \times 14$ & Q345B \\
\hline Brace pipes & $\mathrm{P} 273 \times 10$ & Q345B \\
\hline Outer diagonal cable & $\Phi 7 \times 151$ & $1770 \mathrm{MPa}$ \\
\hline Outer hoop cable & $\Phi 7 \times 421$ & $1770 \mathrm{MPa}$ \\
\hline Paunch cables & $\Phi 7 \times 13$ & $1770 \mathrm{MPa}$ \\
\hline Inner diagonal cables & $\Phi 7 \times 19$ & $1770 \mathrm{MPa}$ \\
\hline Inner hoop cables & $\Phi 7 \times 31$ & $1770 \mathrm{MPa}$ \\
\hline Outer paunch bars & $\mathrm{P} 219 \times 8$ & Q345B \\
\hline Inner paunch bars & $\mathrm{P} 114 \times 8$ & Q345B \\
\hline Appended cables for purpose of circular stability & $\Phi 7 \times 13$ & $1770 \mathrm{MPa}$ \\
\hline
\end{tabular}

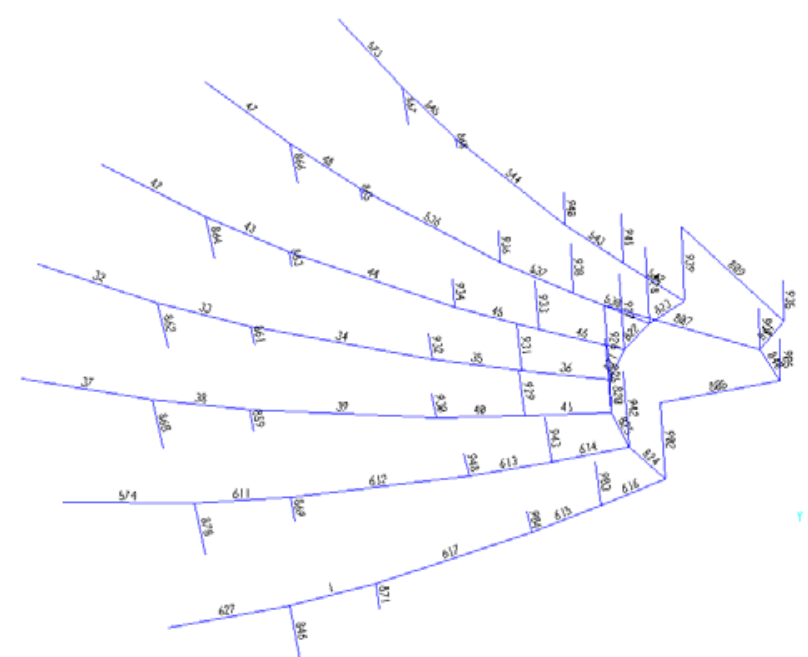

Figure 13. Element No. of 1/4 of Upper Single-layer Reticulated Shell 
Table 2. Pretension Distribution of Lower Cable-bar System

\begin{tabular}{|c|c|c|c|c|c|}
\hline Element No. & Pretension/kN & Section size & Element No. & Pretension $/ \mathrm{kN}$ & Section size \\
\hline 627 & 1826 & $\Phi 7 \times 151$ & 807 & 306 & $\Phi 7 \times 19$ \\
\hline 1 & 1788 & $\Phi 7 \times 151$ & 809 & 296 & $\Phi 7 \times 19$ \\
\hline 617 & 1761 & $\Phi 7 \times 151$ & 840 & 389 & $\Phi 7 \times 31$ \\
\hline 615 & 1725 & $\Phi 7 \times 151$ & 841 & 386 & $\Phi 7 \times 31$ \\
\hline 616 & 1725 & $\Phi 7 \times 151$ & 846 & 126 & $\Phi 7 \times 13$ \\
\hline 574 & 1800 & $\Phi 7 \times 151$ & 871 & 134 & $\Phi 7 \times 13$ \\
\hline 611 & 1760 & $\Phi 7 \times 151$ & 870 & 128 & $\Phi 7 \times 13$ \\
\hline 612 & 1729 & $\Phi 7 \times 151$ & 869 & 137 & $\Phi 7 \times 13$ \\
\hline 613 & 1696 & $\Phi 7 \times 151$ & 860 & 130 & $\Phi 7 \times 13$ \\
\hline 614 & 1693 & $\Phi 7 \times 151$ & 859 & 142 & $\Phi 7 \times 13$ \\
\hline 37 & 1747 & $\Phi 7 \times 151$ & 862 & 133 & $\Phi 7 \times 13$ \\
\hline 38 & 1705 & $\Phi 7 \times 151$ & 861 & 150 & $\Phi 7 \times 13$ \\
\hline 39 & 1671 & $\Phi 7 \times 151$ & 864 & 137 & $\Phi 7 \times 13$ \\
\hline 40 & 1644 & $\Phi 7 \times 151$ & 863 & 159 & $\Phi 7 \times 13$ \\
\hline 41 & 1642 & $\Phi 7 \times 151$ & 866 & 141 & $\Phi 7 \times 13$ \\
\hline 32 & 1692 & $\Phi 7 \times 151$ & 865 & 175 & $\Phi 7 \times 13$ \\
\hline 33 & 1649 & $\Phi 7 \times 151$ & 867 & 152 & $\Phi 7 \times 13$ \\
\hline 34 & 1610 & $\Phi 7 \times 151$ & 868 & 189 & $\Phi 7 \times 13$ \\
\hline 35 & 1590 & $\Phi 7 \times 151$ & 904 & -121 & $\mathrm{P} 219 \times 8$ \\
\hline 36 & 1588 & $\Phi 7 \times 151$ & 903 & -2 & P219×8 \\
\hline 42 & 1631 & $\Phi 7 \times 151$ & 902 & -269 & P219×8 \\
\hline 43 & 1585 & $\Phi 7 \times 151$ & 948 & -125 & $\mathrm{P} 219 \times 8$ \\
\hline 44 & 1540 & $\Phi 7 \times 151$ & 943 & -13 & P219×8 \\
\hline 45 & 1526 & $\Phi 7 \times 151$ & 942 & -134 & P219×8 \\
\hline 46 & 1525 & $\Phi 7 \times 151$ & 930 & -129 & $\mathrm{P} 219 \times 8$ \\
\hline 47 & 1609 & $\Phi 7 \times 151$ & 929 & -17 & P219×8 \\
\hline 48 & 1559 & $\Phi 7 \times 151$ & 925 & -128 & $\mathrm{P} 219 \times 8$ \\
\hline 536 & 1507 & $\Phi 7 \times 151$ & 932 & -135 & $\mathrm{P} 219 \times 8$ \\
\hline 537 & 1497 & Ф $7 \times 151$ & 931 & -18 & P219×8 \\
\hline 538 & 1496 & $\Phi 7 \times 151$ & 926 & -235 & $\mathrm{P} 219 \times 8$ \\
\hline 573 & 1643 & $\Phi 7 \times 151$ & 934 & -140 & $\mathrm{P} 219 \times 8$ \\
\hline 545 & 1586 & $\Phi 7 \times 151$ & 933 & -26 & $\mathrm{P} 219 \times 8$ \\
\hline 544 & 1509 & $\Phi 7 \times 151$ & 927 & -114 & P219×8 \\
\hline 543 & 1501 & $\Phi 7 \times 151$ & 936 & -154 & P219×8 \\
\hline 542 & 1500 & $\Phi 7 \times 151$ & 938 & -31 & P219×8 \\
\hline 824 & 6083 & $\Phi 7 \times 421$ & 928 & -119 & $\mathrm{P} 219 \times 8$ \\
\hline 825 & 6079 & $\Phi 7 \times 421$ & 940 & -165 & P219×8 \\
\hline 820 & 6072 & $\Phi 7 \times 421$ & 941 & -36 & P219×8 \\
\hline 821 & 6060 & $\Phi 7 \times 421$ & 939 & -218 & P219×8 \\
\hline 822 & 6054 & $\Phi 7 \times 421$ & 905 & -97 & $\mathrm{P} 114 \times 8$ \\
\hline 823 & 6048 & $\Phi 7 \times 421$ & 937 & -93 & $\mathrm{P} 114 \times 8$ \\
\hline 805 & 336 & $\Phi 7 \times 19$ & 935 & -90 & $\mathrm{P} 114 \times 8$ \\
\hline
\end{tabular}

After these work in Section 2.1 and Section 2.2 constituting system is finished. Next is to do load/action effects analysis according to national code of practices. 


\section{LOAD/ACTION EFFECTS-MEMBERS' SECTION DESIGN}

In general, structural performance denotes a structure or an assembly behaves well (safe/stable, comfortable, reliable) when subject to possible loads/actions during its lifecycle. Performance based design needs the designer to preset or adjust the structure mechanical property, wind induced response, acceleration and so on by modifying the structural type, member section, or boundary conditions.

\subsection{Load/action Conditions}

Load/action conditions are one of the most important conditions of practical structural design. In the current Chinese load code of practice load/action and their corresponding combinations are given out and specified in details. The standard value of load/action is based on statistical analysis of materials, meteorological record of wind speed, snow, temperature, earthquake and so on. Standard value of dead load is $0.60 \mathrm{kN} / \mathrm{m}^{2}$. Standard value of live load is $0.50 \mathrm{kN} / \mathrm{m}^{2}$. Basic wind pressure at the height of $10 \mathrm{~m}$ with a return period of 100 years is $0.70 \mathrm{kN} / \mathrm{m}^{2}$. Snow load with

return period 100 years is $0.40 \mathrm{kN} / \mathrm{m}^{2}$. Temperature change is considered from $+25^{\circ} \mathrm{C}$ to $-25^{\circ} \mathrm{C}$.

Seismic load is not significant at the construction site.

Load analysis is based on the current code of practice of structural design. Many load combination cases can be analyzed. Geometrical nonlinear analysis is necessary. The results may be checked automatically with respect to the maximum deflection (Table 3) and the maximum stress ratio of members (Table 4).

\subsection{Verification in Ultimate Serviceability Limit Sstates}

From Table 3 it is shown that Dead + wind load case gives rise to the largest nodal displacement. Displacement to span ratio is $1 / 406$. Semi-span live load is more dangerous than uniformly distributed live load. Temperature effects are not significant. This is rational for a self-equilibrated structural system.

Table 3. Maximum Deflection

\begin{tabular}{|c|c|c|c|}
\hline \multicolumn{2}{|c|}{ Load cases combination } & Maximum deflection/mm & Direction \\
\hline 1 & Dead & $-28.8(1 / 4444)$ & downward \\
\hline 2 & Dead + Live & $-147.4(1 / 868)$ & downward \\
\hline 3 & $\begin{array}{c}\text { Dead + Upper semi-span } \\
\text { live }\end{array}$ & $-273.4(1 / 468)$ & downward \\
\hline 4 & $\begin{array}{c}\text { Dead + Left semi-span } \\
\text { live }\end{array}$ & $-211.5(1 / 607)$ & downward \\
\hline 5 & Dear + Temperature rise & $-46.8(1 / 2735)$ & downward \\
\hline 6 & $\begin{array}{c}\text { Dead + Temperature } \\
\text { decrease }\end{array}$ & $-76.1(1 / 1681)$ & upward \\
\hline 7 & Dead+Wind & $315.3(1 / 406)$ & \\
\hline
\end{tabular}




\subsection{Verification in Ultimate Load-carrying Capacity Limit States}

Table 4 is the maximum stress ratios of each member under possible load cases combination. Stress ratios of beam element do not exceed 0.9. The maximum internal forces in cables do not exceed $50 \%$ of their breaking stress. Stress check of upper steel ringbeam does not consider the contribution of concrete materials.

Table 4. Maximum stress ratios

\begin{tabular}{|l|l|}
\hline \multicolumn{1}{|c|}{ Section size } & Stress ratio \\
\hline P1700X35 with C40 concrete inside & 0.37 \\
\hline BOX600X400X16X20 & 0.70 \\
\hline BOX900X400X30X30 & 0.68 \\
\hline P1000X30 & 0.21 \\
\hline P114X8 & 0.43 \\
\hline P219X8 & 0.58 \\
\hline P273X10 & 0.55 \\
\hline P325X12 & 0.66 \\
\hline P402X14 & 0.49 \\
\hline P900X25 & 0.39 \\
\hline$\Phi 7 X 13$ & 0.42 \\
\hline$\Phi 7 X 151$ & 0.34 \\
\hline$\Phi 7 X 19$ & 0.43 \\
\hline$\Phi 7 X 31$ & 0.31 \\
\hline$\Phi 7 X 421$ & 0.41 \\
\hline
\end{tabular}

This section only summarizes strength and deflection results under possible load cases. Other structural performance such as modal analysis, wind-induced vibration analysis, nonlinear geometrical stability analysis, construction sequence simulation, and so on will be discussed in details in other papers.

\section{JOINT DESIGN}

Joint design needs careful FEM analysis using solid element. Joints should be designed with enough strength, stiffness, and reliability. Second, joints should not break before cable breaking. Third, joints' deflection should not affect the structure mechanical property. A special joint when diagonal cable penetrating the upper corresponding beam member is put forward in Figure 14. The advantage of this joint design lies in its water proof function which is very important for architectural design.

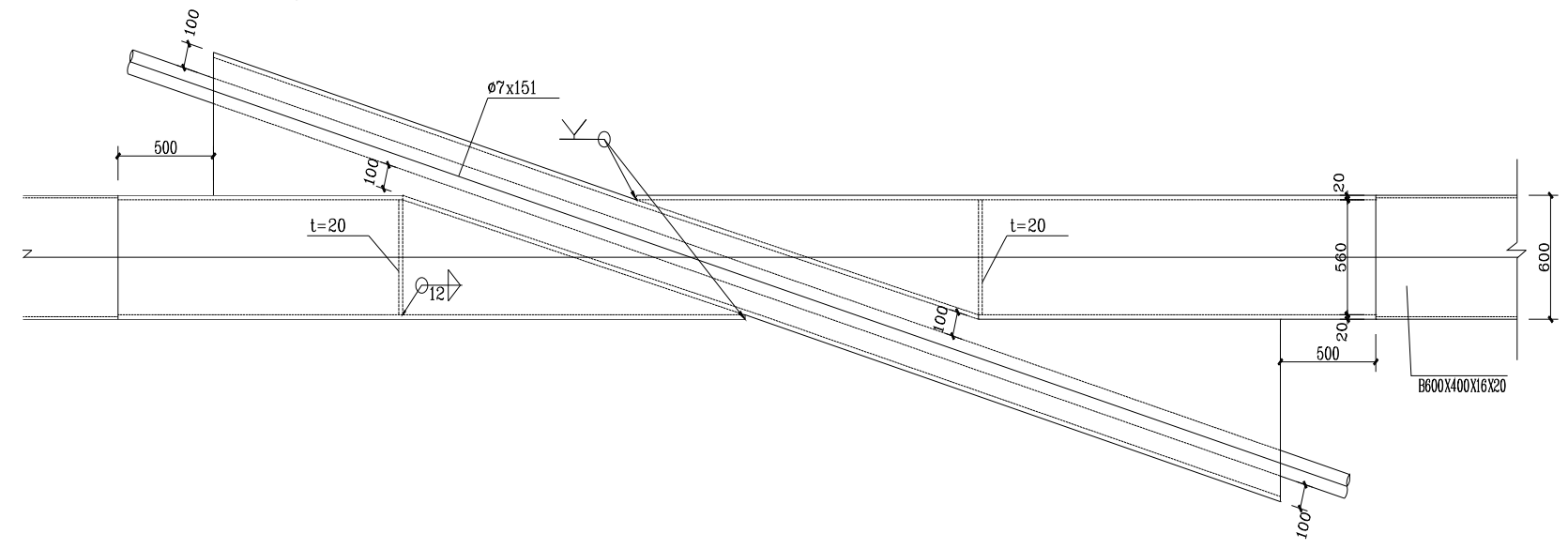

Figure 14. Diagonal Cable Penetrating Upper Steel Beam Joint 


\section{CONCLUSIONS}

A novel large-span cable-frame type of suspended single-layer reticulated shell with free surface is presented in this paper. Emphasis is put on the structural system constitution including form finding of the upper structure and shape determination analysis of the lower cable-bar system. Load/action effects are thoroughly summarized for member sections design. A special joint design when diagonal cables penetrating corresponding upper steel beam is presented.

The key problem of shape finding analysis of lower cable-bar system is of most importance. This algorithm that combines local analysis method and dynamic relaxation method is universally available for general hybrid spatial structures. Further work on more precise shape determination analysis composed of upper and lower structures is needed.

\section{ACKNOWLEDGEMENTS}

The author gratefully acknowledges the support of the Committee of National Science Foundation of China (Grant 50638050 $)$.

\section{REFERENCES}

[1] Kawaguchi, M., Abe, M. and Tatemichi, I., "Design, Tests and Realization of 'Suspen-dome’ System”. J. IASS, 1999; Vol. 40, No. 131, pp. 179-92.

[2] Kawaguchi, M., Abe, M., Hatato, T., Tatemichi, I., Fujiwara, S. and Matsufuji, H. et al., "Structural Tests on the "Suspen-dome" System", Int. Proceedings of IASS Symposium, Atlanta, 1994, pp. 384-92.

[3] Tatemichi, I., Hatato T, Anma Y. and Fujiwara, S., "Vibration Tests on a Full-size Suspen-dome Structure”, Int. J. Space Struct., 1997, Vol. 12, No. 3-4, pp. 217-24.

[4] Kang, W.J., etc., "Analysis and Design of the General and Outmost-ring Stiffened Suspen-dome Structures”, Engineering Structures, 2003, Vol. 25, pp. 1685-1695.

[5] Zhang, Z.H., Dong, S.L. and Tamura, Yukio, "Mechanical Analysis of a Hybrid Spatial Structure Composed of Cables, Bars and Beams”, Int. Journal, Space Structures, 2005, Vol. 20, No. 1, pp. 43-51.

[6] Zhang, Z.H., Dong, S.L. and Tamura, Yukio, "Force Finding Analysis of Hybrid Space Structures”, Int. Journal, Space Structures, 2005, Vol. 20, No. 2, pp. 107-113.

[7] Zhang, M.S., “Theoretical Research on Suspen-dome”, Zhejiang university, Ph.D. Thesis, 2004, Hangzhou. (in Chinese)

[8] Chen, Z.H., Chin, Y.L. and Zhao, J.B., et al., "An Experimental Study on Rigid Suspen-dome”, Journal of Civil Engineering, 2006, Vol. 39, No. 9, pp. 47-53.

[9] Zhang, Z.H., Dong, S.L. and Fu, X.Y., "Structural Design of Lotus Arena: A Large-span Suspen-dome Roof”, Int. Journal, Space Structures, 2009, Vol. 24, No. 3, pp. 129-142.

[10] Zhang, Z.H. and Dong, S.L., "Shape Determination Problem of Spatial Cable-frame Type of Suspended Single-layer Reticulated Shells with Free Surface”, Int. J. Space Structures, 2010, Vol. 25, No. 1, pp. 45-56.

[11] Levy, M.P., “The Georgia Dome and Beyond Achieving Light Weight-long Span Structures”, Proc. IASS-ASCE, Int. Symp. Atlanta, USA, 1994, pp. 560-562.

[12] Geiger, D.H., Stefaniuk, A. and Chen, D., "The Design and Construction of Two Cable Domes for the Korean Olympics", Proc. of the IASS Symposium on Shells, Membranes and Space Frames, Osaka, Japan, 1986, Vol. 2, pp. 265-272. 
[13] Zhang, Z.H., "Proper Shape Analysis of Spatial Cable-frames", International Journal of Space Structures, 2010, July, submitted.

[14] Zhang, Z.H., "Desk Study of Beam/Truss-string Structures”, International Journal of Space Structures, 2010, July, submitted.

[15] Barnes, M.R., "Applications of Dynamic Relaxation to the Design and Analysis of Cable, Membrane, and Pneumatic Structures”, 2nd Int. Conf. on Space Structures, Guildford, 1975.

[16] Oakley, David R. and Knight, Norman F.”, Adaptive Dynamic Relaxation Algorithm for Non-linear Hyperelastic Structures”, Part I. Formulation. Computer Method in Applied Mechanics and Engineering, 1995, Vol. 126, pp. 67-89.

[17] Scheck, H.J., "The Force Density Method for Form-finding and Computation of General Networks”, Computer Method in Applied Mechanics and Engineering, 1974, Vol. 3, No. 1, pp. 115-134.

[18] National Science and Technology Research Center for Computation and Visualization of Geometric Structures (The Geometry Center), University of Minnesota. 1993.

[19] Sandwell, David T., "Biharmonic Spline Interpolation of GEOS-3 and SEASAT Altimeter Data", Geophysical Research Letters, 1987, Vol. 2, pp. 139-142. 